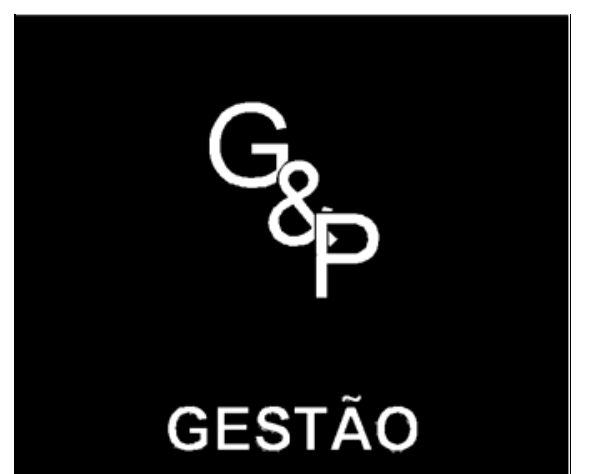

$\&$

PRODUÇÃO

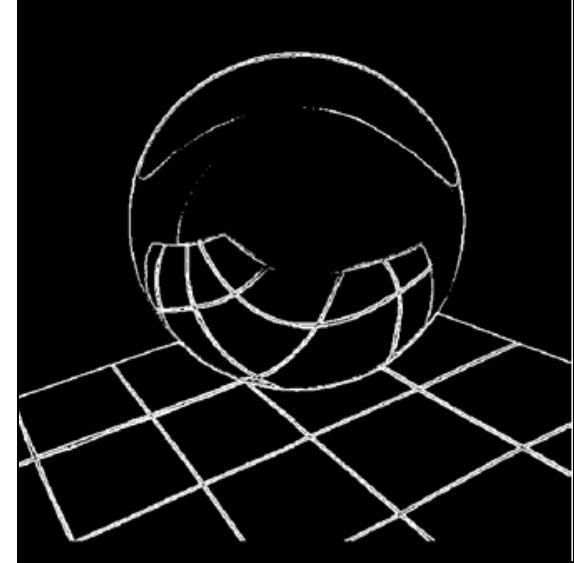

v.5, n.3, p. 239-258, dez. 1998

\section{MEDIÇÃO DO DESEMPENHO DE TRÊS LINHAS DE FABRICAÇÃO \\ INSTALADAS EM AMBIENTES DE MANUFATURA AVANÇADA UTILIZANDO O MODELO SAPROV}

\author{
Cosmo Severiano Filho \\ Universidade Federal da Paraíba \\ Programa de Pós-Graduação em Engenharia de Produção \\ Caixa Postal 5045 - CEP 58051-900 - João Pessoa - PB \\ email: cosmosf@producao.ct.ufpb
}

\title{
Resumo
}

A avaliação do desempenho constitui matéria de relevante interesse para as organizações que têm implantado novas tecnologias de produção e de gestão. Este artigo avalia o desempenho em termos de produtividade, flexibilidade e qualidade de três linhas de produção, instaladas em ambientes avançados de manufatura, utilizando a metodologia do sistema SAPROV - Sistema de Avaliação da Produtividade Vetorial. A pesquisa realizada para teste e validação da metodologia SAPROV permitiu o processamento da avaliação por quatro procedimentos básicos: (1) determinação dos critérios de valor da manufatura; (2) determinação dos padrões referenciais de desempenho para cada critério de valor; (3) auditoria para avaliação do desempenho dos critérios de valor adotados na manufatura; e (4) aplicação dos indicadores para avaliação técnica e econômica do desempenho da manufatura. Neste sentido, o artigo analisa o procedimento de avaliação realizado, discutindo os resultados obtidos em cada uma das linhas, de modo a comprovar a legitimação do modelo SAPROV.

Palavras-chave: manufatura avançada, qualidade, produtividade, flexibilidade, Modelo SAPROV.

\section{Introdução}

$\mathrm{O}$ desenvolvimento tecnológico dos últimos anos e o processo de globalização dos mer- cados impuseram a modernização dos sistemas produtivos, em quase todas as economias do mundo. A nova ordem econômica estabelece paradigmas modernos de produção, orientados 
para a obtenção de desempenhos superiores, em um ambiente cada vez mais dinâmico e flexível. São os conceitos emergentes dessa nova ordem estratégica, traduzidos pela tríade produtividade, qualidade total e flexibilidade, que constituem os principais elementos das chamadas tecnologias avançadas de produção (Advanced Manufacturing Technologies - AMT's).

A implantação dessas tecnologias, no todo ou em parte, permite incorporar profundas alterações nos sistemas produtivos, permitindo a obtenção de elevados ganhos de produtividade, maior valor agregado ao produto, bem como condições de flexibilidade em vários níveis da produção. Desse modo, os sistemas produtivos que têm incorporado essas tecnologias passaram a ser definidos na literatura como sistemas avançados de produção.

A maior parte destas tecnologias faz uso intensivo de recursos computacionais (hardwares e softwares), como é o caso dos sistemas CAD (Projeto Auxiliado por Computador); CAE (Engenharia Auxiliada por Computador); CAM (Manufatura Auxiliada por Computador); CAPP (Planejamento do Processo Auxiliado por Computador); CAQ (Qualidade Auxiliada por Computador); CIM (Manufatura Integrada por Computador); CNC (Comando Numérico Computadorizado); EDI (Intercâmbio Eletrônico de Dados); FMC (Célula Flexível de Manufatura); FMS (Sistema Flexível de Manufatura); MRP (Planejamento das Necessidades de Material); MRP II (Planejamento dos Recursos da Manufatura); OPT (Tecnologia de Produção Otimizada); e toda a gama de equipamentos de automação e robótica.

Outras tecnologias dizem respeito a princípios e elementos conceituais relacionados com a organização e gestão do sistema produtivo. Em geral, tratam-se de tecnologias que definem procedimentos para o gerenciamento da manufatura, associados ao estabelecimento e consecução de metas de qualidade e produtividade, pelo envolvimento pleno dos recursos humanos. Nesta categoria incluem-se, dentre outros: $A B C$ (Custeio Baseado em Atividades); ABM (Gestão
Baseada em Atividades); JIT (Just-In-Time); KANBAN (Cartões para Puxar a Produção); MC (Manufatura Celular); PFA (Análise do Fluxo de Produção); TQC (Controle de Qualidade Total); TQM (Gestão da Qualidade Total).

Analisando os aspectos operacionais deste novo ambiente de produção, WEILL et al. (1991) afirmam que a introdução de tecnologias hardwares e softwares de manufatura, dirigidas para a otimização dos processos produtivos, desenvolve uma nova base de competitividade para as organizações, cujo objetivo é a obtenção de resultados superiores.

Este artigo analisa o processo de medição do desempenho de uma organização que implantou uma gama de novas tecnologias de produção e gestão, e tem por finalidade apresentar a modelagem de um sistema de avaliação do desempenho que contempla um conjunto de parâmetros estreitamente relacionados com estas novas tecnologias. Portanto, é exatamente neste aspecto, o do desempenho dos sistemas de manufatura avançada, que se situa o escopo deste artigo.

\section{O "Porquê" da Medição do Desempenho em Ambientes de Manufatura Avançada}

A justificativa do presente trabalho se prende ao fato de que a medição do desempenho de sistemas de manufatura avançada constitui um campo do conhecimento relativamente novo, como é o caso dos estudos sobre a aplicabilidade das tecnologias avançadas de produção. De acordo com KAPLAN (1983), as primeiras pesquisas sobre o assunto, notadamente as das escolas americanas de Harward e de Boston, versaram sobre a modelagem e adequação de sistemas contábeis em ambientes de manufatura avançada, determinando importantes passos para outras pesquisas.

Os estudos de RICHARDSON \& GORDON (1980), MOHANTY \& RASTOGI (1986) e SON \& PARK (1987) representam os primeiros esforços de contribuição para a avaliação da produtividade em ambientes que utilizam sistemas de manufatura avançada. Esses estudos 
estão orientados, principalmente, para a definição de variáveis globais de desempenho, com o objetivo de estabelecer mecanismos de avaliação econômica das tecnologias modernas.

$\mathrm{Na}$ sua abordagem sobre o assunto, SON (1987) considera que a pesquisa sobre o desenvolvimento de sistemas de avaliação econômica mais seguros e particularmente adaptados às novas configurações dos sistemas produtivos está ainda em estágio embrionário. O autor sustenta que existe uma enorme dificuldade para se quantificar os benefícios econômicos decorrentes das AMT's, uma vez que as estruturas convencionais de custos não permitem a mensuração de muitos valores importantes da manufatura avançada, como por exemplo, os níveis de balanceamento das linhas e de sincronização dos fluxos, o grau de flexibilidade do sistema operacional, entre outros.

As abordagens desenvolvidas por KULATILAKA (1984), MEREDITH (1986), MILTENBURG \& KRINSKY (1987), PARK \& SON (1988), MOERMAN (1988) e SON (1990) emprestam igualmente grande contribuição à avaliação do desempenho de técnicas avançadas de produção. No entanto, é a partir do trabalho de SON (1991) que surge o primeiro modelo devidamente sistematizado para a avaliação econômica de sistemas de produção que utilizam AMT's. Neste sentido, a justificativa de realização deste artigo representa um esforço de contribuição ao conhecimento disponível sobre a avaliação do desempenho de sistemas de manufatura avançada, descrevendo um modelo desenvolvido com este objetivo.

\section{Modelagem do SAPROV para Avaliação do Desempenho}

$\mathrm{E}$ sta seção apresenta os conceitos e premissas de base relativos ao sistema de avaliação da produtividade vetorial para a manufatura avançada (SAPROV), desenvolvido em 1995 junto ao Programa de Doutoramento em Engenharia de Produção \& Sistemas da Universidade Federal de Santa Catarina. O Sistema SAPROV foi testado em três linhas de fabricação de uma empresa francesa que trabalha com sistemas de manufatura avançada, por meio de missão de pesquisa realizada junto ao Institut de Gestion Internationale Agro-Alimentaire na França.

O modelo teórico do SAPROV pressupõe o rastreamento dos diversos vetores do desempenho operacional de uma organização, em três dimensões distintas de investigação: identificação (rastreamento dos vetores), mensuração (medição e registro) e avaliação (análise comparativa dos vetores). Assim sendo, a produtividade é definida operacionalmente como a relação entre o que é gerado por um sistema organizacional e o que entra nesse sistema, ou seja, a relação entre o “'output' total produzido e os 'inputs' totais requeridos”.

As expressões “output" total produzido e "inputs" totais requeridos assumem aqui uma grandeza absolutamente maior do que aquela definida por suas terminologias correntes. Referem-se, na verdade, não apenas às quantidades físicas de unidades produzidas e de insumos utilizados, mas ao conjunto de atributos gerados (produtividade, qualidade e flexibilidade do volume de produção) e de critérios observados (produtividade, qualidade e flexibilidade do volume de recursos) pelo sistema organizacional em operação.

A definição do eixo teórico deste sistema de avaliação pressupõe o delineamento de alguns conceitos básicos, conforme evidenciado anteriormente. Estes conceitos constituem os fundamentos de base do sistema proposto e têm como função a explicitação dos princípios considerados no processo de avaliação. A Tabela 1 contém uma sinopse desses conceitos, bem como os princípios de funcionalidade operacional que caracterizam a formulação do sistema em referência.

\subsection{Estrutura Técnica e Procedimentos Operacionais do SAPROV}

De acordo com os conceitos de base do sistema em referência, os quatro procedimentos aqui apresentados objetivam avaliar o desem- 
Tabela 1 - Sinopse ilustrativa dos princípios de base do sistema SAPROV

\begin{tabular}{|c|c|}
\hline CONCEITO & DEFINIÇÃO E PRINCÍPIO DE BASE \\
\hline $\begin{array}{l}\text { Desempenho Global } \\
\text { da Produção }\end{array}$ & $\begin{array}{l}\text { Medida de produtividade global da manufatura, dada pela razão entre o resultado operacio- } \\
\text { nal da produção (output) e os custos totais requeridos e gerados pelo processo operacional } \\
\text { empregado. } \\
\text { Princípio SAPROV } 1 \text { - O processo de avaliação deve aferir um resultado que indique o } \\
\text { estado de entropia ou de homeostase dos elementos avaliados. }\end{array}$ \\
\hline $\begin{array}{c}\text { Sistema de } \\
\text { Manufatura Avançada }\end{array}$ & $\begin{array}{l}\text { Configuração de recursos combinados, utilizando uma elevada carga de densidade e } \\
\text { competência tecnológica, para a produção de bens tangíveis e intangíveis. O enfoque } \\
\text { "avançado" decorre da elevada utilização de tecnologias avançadas de manufatura (AMT's), } \\
\text { responsáveis pelo alto desempenho operacional desses sistemas. } \\
\text { Princípio SAPROV } 2 \text { - Os critérios de avaliação devem permitir uma classificação das } \\
\text { variáveis envolvidas, respeitando seus graus de valores e níveis de desempenho. }\end{array}$ \\
\hline $\begin{array}{c}\text { Produtividade Vetorial } \\
\text { da Manufatura }\end{array}$ & $\begin{array}{l}\text { Medida global do desempenho vetorial de um sistema produtivo, dada pela relação entre os } \\
\text { atributos gerados e os critérios observados na produção de bens e serviços. Esta medida } \\
\text { deve ser expressa por um vetor de atributos, representando o conjunto de valores incorpo- } \\
\text { rados pelo processo de produção. } \\
\text { Princípio SAPROV } 3 \text { - O sistema de avaliação deve permitir a elaboração de uma medida } \\
\text { única (vetorial e específica) do valor total das variáveis avaliadas, quer seja no plano } \\
\text { quantitativo, quer seja no plano qualitativo. }\end{array}$ \\
\hline $\begin{array}{l}\text { Desempenho Total } \\
\text { em Qualidade }\end{array}$ & $\begin{array}{l}\text { Medida de produtividade vetorial de um sistema produtivo, definida em atributos de } \\
\text { qualidade incorporados na produção de outputs. Esta medida deve expressar os níveis de } \\
\text { confiabilidade, rejeição, conformidade, retrabalho, reclamações de defeitos e outras } \\
\text { variáveis relacionadas com o fator qualidade. } \\
\text { Princípio SAPROV } 4 \text { - A avaliação dos atributos gerados por um sistema produtivo, deve } \\
\text { levar em consideração uma correta ponderação das variáveis presentes em sua estrutura de } \\
\text { valor. }\end{array}$ \\
\hline $\begin{array}{l}\text { Desempenho Total } \\
\text { em Flexibilidade }\end{array}$ & $\begin{array}{l}\text { Medida de produtividade vetorial de um sistema produtivo, definida em atributos de } \\
\text { flexibilidade incorporados na produção de outputs. Esta medida deve expressar os níveis de } \\
\text { adaptabilidade e reatividade do sistema produtivo, pelo enxugamento dos custos de espera, } \\
\text { set-up, ociosidade e estoque, além de outras variáveis relacionadas com o fator flexibilidade. } \\
\text { Princípio SAPROV } 5 \text { - As unidades de medida em um sistema de avaliação devem ser } \\
\text { prescritas por critérios dinâmicos e plurais de mensuração, de modo que as variáveis } \\
\text { analisadas possam ser comparadas simultaneamente, por dois ou mais indicadores. }\end{array}$ \\
\hline $\begin{array}{c}\text { Tecnologia Avançada } \\
\text { de Manufatura }\end{array}$ & $\begin{array}{l}\text { Conjunto de técnicas e métodos avançados de manufatura, de natureza hardware e } \\
\text { software, para aplicação nas funções de planejamento, concepção, controle, execução e } \\
\text { acompanhamento da produção. } \\
\text { Princípio SAPROV } 6 \text { - Um sistema de avaliação deve funcionar como um "painel de } \\
\text { controle" da gestão empresarial, fornecendo informações múltiplas e simultâneas para } \\
\text { apoiar a decisão gerencial. }\end{array}$ \\
\hline
\end{tabular}

penho operacional da manufatura avançada, em duas dimensões distintas: a dimensão técnica e a dimensão econômica. Estes procedimentos podem ser definidos como segue:

(1) definição dos critérios de valor da manufatura;

(2) determinação de padrões referenciais de desempenho para cada critério de valor;
(3) instrução de auditoria para avaliar o desempenho dos critérios de valor da manufatura;

(4) aplicação dos indicadores de base para a avaliação do desempenho técnico e econômico da manufatura.

A Tabela 2 apresenta o Modelo de Referência SAPROV 1010, que define a natureza destes procedimentos e fixa instruções explicativas 
Tabela 2 - Modelo de referência SAPROV 1010

Fonte: SEVERIANO FILHO, 1995

SAPROV - MOD.1010

\section{PROCEDIMENTOS DE REFERÊNCIA PARA AVALIAÇÃO DO DESEMPENHO}

\begin{tabular}{|c|c|}
\hline SEQÜÊNCIA DE BASE & INSTRUÇÕES EXPLICATIVAS \\
\hline $\begin{array}{l}\text { (1) Definição dos parâmetros de } \\
\text { valor da manufatura }\end{array}$ & $\begin{array}{l}\text { - O processo de definição dos parâmetros de valor da manufatura deve } \\
\text { focalizar os princípios e objetivos dos métodos e técnicas empregados pelo } \\
\text { sistema produtivo. Exemplo: se o sistema de produção utiliza manufatura } \\
\text { celular, um desses parâmetros de valor deve ser o tempo médio de set-up } \\
\text { requerido. }\end{array}$ \\
\hline $\begin{array}{l}\text { (2) Determinação de padrões } \\
\text { referenciais de desempenho para } \\
\text { cada parâmetro de valor. }\end{array}$ & $\begin{array}{l}\text { - Os padrões referenciais de desempenho devem ser determinados a partir } \\
\text { dos critérios de excelência da empresa. Esse conceito de excelência deve } \\
\text { funcionar como um princípio de melhoramento contínuo, de modo que os } \\
\text { padrões de referência mudem no tempo. Assim sendo, para cada parâmetro } \\
\text { de valor deve ser determinado um padrão de referência, afim de que o seu } \\
\text { desempenho possa ser avaliado. }\end{array}$ \\
\hline $\begin{array}{l}\text { (3) Instrução de auditoria para } \\
\text { avaliar o desempenho dos } \\
\text { parâmetros de valor da } \\
\text { manufatura. }\end{array}$ & $\begin{array}{l}\text { - Os parâmetros de valor da manufatura devem ser previamente auditados, a } \\
\text { fim de que o processo de avaliação possa ser efetuado. A auditoria é feita por } \\
\text { um cheklist dos parâmetros de valor, registrando-se o desempenho efetivo de } \\
\text { cada um deles. Em seguida, compara-se esse resultado com o resultado } \\
\text { padrão de referência, anotando-se a taxa de produtividade obtida e a sua } \\
\text { variação em relação ao valor de referência. }\end{array}$ \\
\hline $\begin{array}{l}\text { (4) Aplicação dos indicadores de } \\
\text { base para a avaliação do } \\
\text { desempenho técnico e econômi- } \\
\text { co da manufatura }\end{array}$ & $\begin{array}{l}\text { A aplicação dos indicadores de base deve permitir a avaliação do desempenho } \\
\text { operacional da produção, indicando os pontos fortes e os pontos fracos das } \\
\text { técnicas e dos métodos empregados. Esses indicadores apontam os } \\
\text { desempenhos numéricos da manufatura (técnico e econômico), fornecendo } \\
\text { uma base de dados necessários para a avaliação do desempenho qualitativo } \\
\text { da produção. }\end{array}$ \\
\hline
\end{tabular}

acerca de sua funcionalidade e execução. Observe que os procedimentos em referência demandam o envolvimento de uma equipe de avaliação, com suficiente conhecimento das atividades operacionais da organização, bem como dotada de competência técnica para o exercício do processo de avaliação.

A definição dos critérios de valor da manufatura avançada constitui um processo de estudo e reflexão sobre os novos paradigmas de produção, seus princípios, metas e objetivos. Eles devem refletir a natureza e configuração do sistema de produção empregado, assim como das técnicas e dos métodos operacionais a ele associados.

Neste sentido, o conhecimento gerado sobre os processos de fabricação e as tecnologias utilizadas é tão importante que a equipe de avaliação deve instituir e monitorar um sistema específico de informações, para apoiar a análise da avaliação em pauta.

O segundo procedimento metodológico do Sistema SAPROV constitui a fase de definição dos padrões de referência para os critérios de valor da produção. Este processo está baseado nos objetivos de excelência da empresa, de modo que a própria equipe de avaliação é quem deverá determiná-los. Trata-se de um procedimento delicado, exigindo consenso entre a equipe de avaliação e a alta administração da empresa.

Associado ao conceito de excelência da organização, os indicadores de desempenho da concorrência e/ou as medidas setoriais de benchmarking podem constituir igualmente fatores de referência neste processo. A montagem e manutenção de um sistema permanente e sincronizado de informações sobre o sistema 
operacional da empresa pode auxiliar bastante este processo.

A terceira fase de operações da metodologia SAPROV refere-se à auditoria para a avaliação do desempenho dos critérios de valor. Nesta fase, o desempenho desses critérios é avaliado em relação aos padrões de referência estabelecidos na fase anterior, conforme instrução explicativa apresentada na Tabela 2.

Para fins de organização do processo de auditoria, os critérios de valor devem ser alinhados em três categorias de avaliação, de acordo com a natureza do objetivo que ele induz, ou seja, objetivo de produtividade, objetivo de flexibilidade ou objetivo de qualidade.

A última fase de procedimentos corresponde às operações de aplicação dos indicadores de base para a avaliação do desempenho. Os indicadores programados permitem uma avaliação quantitativa e qualitativa do desempenho operacional, fornecendo os resultados numéricos da manufatura e indicando os pontos fortes e os pontos fracos dos métodos e técnicas empregados pela configuração produtiva.

Neste sentido, o sistema propõe uma grade de oito indicadores de avaliação, sendo que quatro deles correspondem a medidas de desempenho técnico e quatro a medidas de desempenho econômico. Os indicadores em referência estão delineados no sistema da seguinte forma:

\section{MEDIDAS DE DESEMPENHO TÉCNICO}

(1) Índice de Indução de Produtividade - IIP

(2) Índice de Indução de Flexibilidade - IIF

(3) Índice de Indução de Qualidade - IIQ

(4) Índice de Produtividade Vetorial da Manufatura Avançada - IPVMA

\section{MEDIDAS DE DESEMPENHO ECONÔMICO}

(5) Índice de Desempenho Total em Produtividade IDTP

(6) Índice de Desempenho Total em Flexibilidade IDTF

(7) Índice de Desempenho Total em Qualidade IDTQ

(8) Índice de Desempenho Vetorial da Manufatura Avançada - IDVMA
A estrutura de avaliação proposta neste modelo permite a introdução de outros indicadores, de natureza técnica ou econômica, desde que estejam adequadamente identificados com as variáveis de análise das AMT’s. O processo de avaliação é, portanto, dinâmico e flexível, permitindo ajustes e adequações em diversos pontos de sua estrutura. A Tabela 3 esquematiza o Modelo de Referência SAPROV 1015, com a indicação dos principais indicadores a serem utilizados neste processo.

\section{Medição do Desempenho de Três Linhas de Fabricação Utilizando o SAPROV}

Z sta seção apresenta os procedimentos de Uaplicação do sistema SAPROV em três linhas de fabricação instaladas em ambientes de manufatura avançada, contendo a exposição e análise dos resultados obtidos no estudo. Neste sentido, as operações de aplicação do modelo proposto foram executadas de acordo com suas instruções normativas, de modo que os quatro procedimentos operacionais previstos pudessem ser logicamente efetivados.

A aplicação do sistema SAPROV teve por base a realização de um estudo descritivo, envolvendo três linhas de fabricação que operam com tecnologias avançadas de manufatura. A Tabela 4 contém uma sinopse explicativa destas linhas, com a apresentação resumida de suas configurações organizacionais e tecnológicas.

Os dados necessários à aplicação do modelo SAPROV foram coletados diretamente sobre as linhas de fabricação, utilizando-se três instrumentos básicos: (1) a entrevista estruturada por protocolo fixo, (2) a observação sistemática e direta dos procedimentos operacionais das linhas e (3), a análise de relatórios e documentos referentes à produção.

\subsection{Definição dos Critérios de Valor nas Linhas de Fabricação Estudadas}

Em conformidade com o modelo proposto, o procedimento inicial para a avaliação do 
Tabela 3 - Modelo de referência SAPROV 1015

Fonte: Adaptado de SEVERIANO FILHO, 1995

SAPROV - MOD. 1015

SISTEMA DE INDICADORES

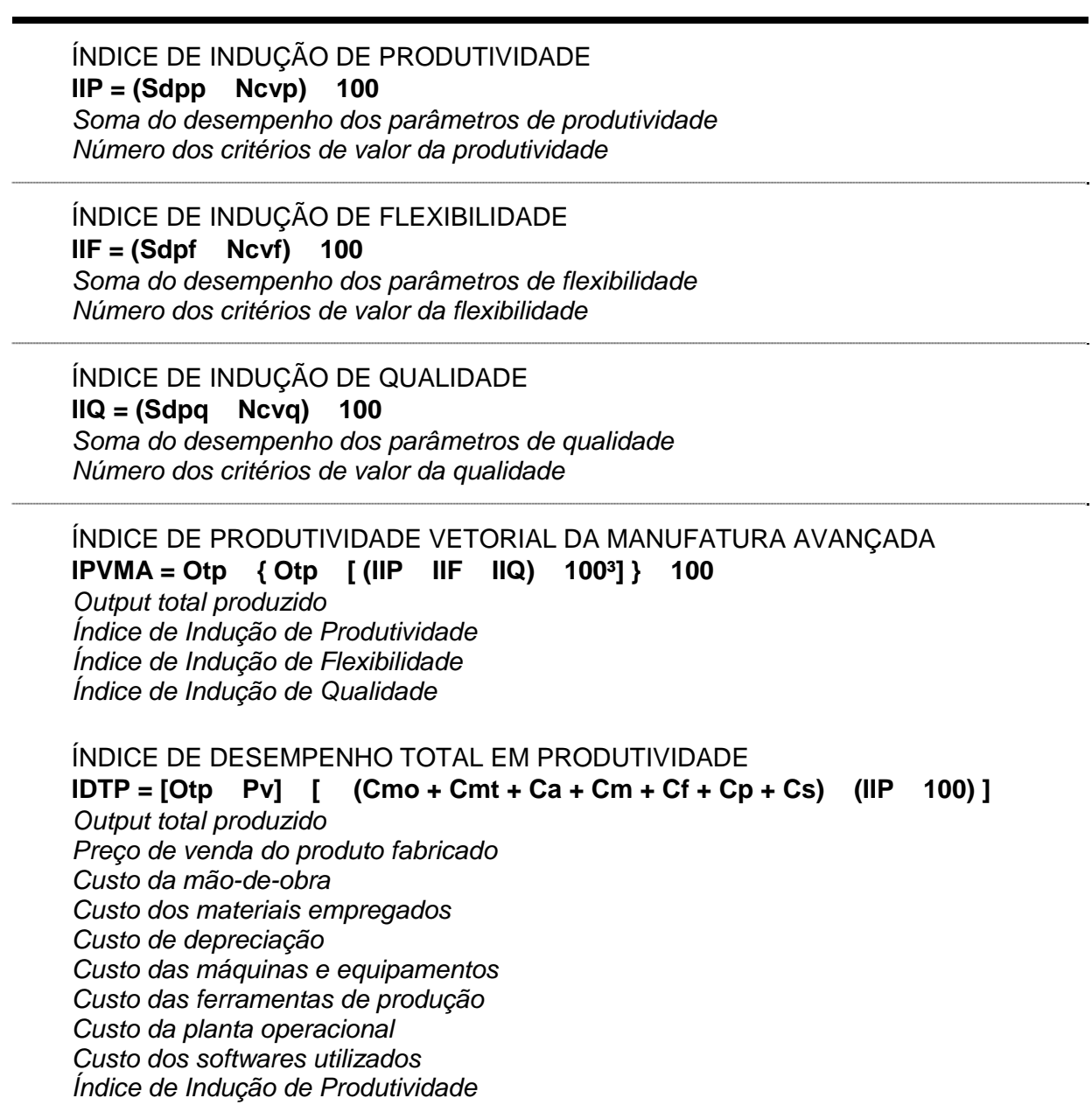

desempenho é a definição dos critérios de valor da manufatura. Assim sendo, este primeiro procedimento operacional foi efetuado com base nas instruções explicativas do Modelo SAPROV 1010, respeitando-se os demais princípios que norteiam o método.

Para fins de definição e organização dos critérios de valor, as linhas de fabricação analisadas foram agrupadas segundo a natureza e as características de seus sistemas de manufatura, conforme mostra a Tabela 4. Neste mesmo sentido, respeitou-se o caráter de confidencialidade da empresa investigada, no que se refere a sua denominação social, seus valores, cifras e outros dados numéricos de seu sistema produtivo.

A Tabela 5 apresenta uma sinopse contendo os critérios de valor das linhas de fabricação, de acordo com o esquema de análise de suas características organizacionais e tecnológicas. Na verdade, o processo de definição destes critérios de valor observou tanto os princípios e a natureza das tecnologias empregadas, como os objetivos e metas da alta administração da empresa.

A metodologia do processo de avaliação não estabelece uma quantidade exata (mínima ou máxima) para os critérios de valor de um sistema 
Tabela 3 - Continuação - Modelo de referência SAPROV 1015

Fonte: Adaptado de SEVERIANO FILHO, 1995

SAPROV - MOD. 1015

CONTINUAÇÃO

ÍNDICE DE DESEMPENHO TOTAL EM FLEXIBILIDADE

IDTF $=\left[\begin{array}{ll}\text { Otp } & \text { Pv }\end{array}\right] \quad$ (Cup + Cw + Coc + Ci) (IIF 100) $]$

Output total produzido

Preço de venda do produto fabricado

Custo total de set-up

Custo total de espera do sistema

Custo total de ociosidade do sistema

Custo total de estoques

Índice de Indução de Flexibilidade

ÍNDICE DE DESEMPENHO TOTAL EM QUALIDADE

IDTQ $\left.=\left[\begin{array}{ll}\text { Otp } & \text { Pv }\end{array}\right]\left[\begin{array}{lll}(C p v+C d f & (I I Q & 100\end{array}\right)\right]$

Output total produzido

Preço de venda do produto fabricado

Custo das ações de prevenção

Custo total de falhas

Índice de Indução de Qualidade

ÍNDICE DE DESEMPENHO VETORIAL DA MANUFATURA AVANÇADA

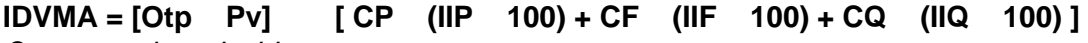

Output total produzido

Preço de venda do produto fabricado

Custo total de produtividade do sistema

Índice de Indução de Produtividade

Custo total de flexibilidade do sistema

Índice de Indução de Flexibilidade

Custo total da qualidade

Índice de Indução da Qualidade

produtivo, de modo que o número exato desses critérios será sempre uma função de dois fatores importantes: o tipo de tecnologia empregado, que definirá a natureza dos métodos de fabricação e os objetivos e metas previstos pela administração, os quais decorrem, quase sempre, das próprias inovações implantadas.

\subsection{Determinação de Padrões Referenciais de Desempenho para os Critérios de Valor da Produção}

Em consonância com os procedimentos de referência do modelo SAPROV, o segundo procedimento operacional tratou da definição dos padrões referenciais de desempenho para cada critério de valor da manufatura, de modo que estes critérios pudessem ser quantitativa e qualitativamente avaliados.
De acordo com as instruções explicativas pertinentes ao modelo, estes padrões de referência foram determinados a partir dos critérios de excelência da empresa estudada. Nesse sentido, encaminhou-se um protocolo fixo à empresa, para que a alta administração apresentasse, em caráter confidencial, os padrões de excelência desejados por sua organização.

Os valores informados constituem metas de excelência a serem alcançadas por cada unidade, em função das inovações tecnológicas implantadas, assim como dos objetivos organogerenciais de cada administração em particular. Desse modo, estes valores representam padrões de desempenho apenas para esta organização, podendo (ou não) serem utilizados como valores de referência em outras unidades similares.

Assim sendo, o procedimento em pauta permitiu atribuir um padrão de desempenho para 
Tabela 4 - Sinopse explicativa das linhas de fabricação analisadas no estudo descritivo

\begin{tabular}{|c|c|}
\hline LINHAS DE PRODUÇÃO & CARACTERÍSTICAS \\
\hline $\begin{array}{l}\text { FABRICAÇÃO 1: BRIOCHE } \\
\text { FABRICAÇÃO 2: PÃO PARISIENSE } \\
\text { FABRICAÇÃO 3: PÃO DE LEITE }\end{array}$ & $\begin{array}{l}\text { Fabricação informatizada de configuração celular, operando } \\
\text { um processo de natureza contínua, com a incorporação das } \\
\text { seguintes técnicas: organização JIT em fluxo puxado (gestão } \\
\text { por reconstituição dos estoques de produtos acabados); } \\
\text { produção em série de pequenos lotes; fabricação auxiliada por } \\
\text { computador; manutenção preventiva e periódica de todas as } \\
\text { instalaçães celulares; automatização dos equipamentos de } \\
\text { produção; controle total e permanente da qualidade (TQC); } \\
\text { formação de operadores multifuncionais; sincronização dos } \\
\text { fluxos e balanceamento permanente da linha. }\end{array}$ \\
\hline
\end{tabular}

cada critério de valor, gerando uma matriz permanente e flexível de informações a ser utilizada para a avaliação das linhas de fabricação analisadas. A Tabela 6 apresenta a estrutura final dessa matriz, com os valores médios atribuídos às linhas.

Observe que estes valores podem ser ajustados no tempo, uma vez que foram elaborados com base no conceito de excelência que cada uma das organizações possui. Considerando, portanto, que a definição de excelência constitui um conceito de melhoramento contínuo, esperase que os seus parâmetros de referência possam melhorar continuamente no tempo.

Uma outra consideração importante, relacionada com a definição técnica destes padrões de referência, diz respeito aos próprios objetivos do sistema SAPROV. Neste sentido, os parâmetros aqui definidos têm como objetivo o acompanhamento e controle do desempenho operacional dos sistemas produtivos, pela comparação, no tempo, dos resultados alcançados pela organização, nos diversos aspectos da estrutura produtiva. Desta forma, os resultados efetivamente alcançados devem ser comparados com os padrões de referência estabelecidos, para se obter um cenário amplo de avaliação do desempenho da manufatura.

\subsection{Auditoria de Avaliação dos Critérios de Valor da Manufatura}

Uma vez definidos os padrões de referência, pode-se executar o terceiro procedimento operacional do Modelo SAPROV, cuja finalidade é a instrução de auditoria para avaliação dos critérios de valor da produção. Trata-se da auditagem dos resultados efetivamente alcançados por cada critério de valor e a comparação destes, com os padrões referenciais de desempenho definidos anteriormente. $\mathrm{O}$ processo de avaliação inclui ainda a determinação da taxa de produtividade obtida, assim como a variação desta em relação ao valor de referência.

Conforme as instruções explicativas do modelo, o processo de auditoria observou o alinhamento dos critérios de valor em três grupos de avaliação, de modo a avaliar separadamente o desempenho em produtividade, em flexibilidade e em qualidade, referente às linhas estudadas. Neste sentido, os dados coletados na pesquisa estão demonstrados nos formulários Modelos de Referência 1012, 1013 e 1014 da estrutura SAPROV, conforme ilustração das Tabelas 7, 8 e 9, respectivamente.

$\mathrm{O}$ auditamento dos dados teve por finalidade a avaliação dos resultados efetivamente obtidos pela manufatura, em relação aos resultados padrões definidos pela empresa. A relação entre estes dois resultados é denominada de taxa de produtividade, cujo valor representa a base de cálculo para a determinação de três índices importantes do sistema de produção, quais sejam: Índice de Indução de Produtividade (IIP); Índice de Indução de Flexibilidade (IIF) e Índice de Indução de Qualidade (IIQ).

A lógica desses indicadores é a da explicitação matemática das operações de produtividade, 
Tabela 5 - Sinopse dos critérios de valor da manufatura na empresa 12.IPM20 Fonte: SEVERIANO FILHO, 1995

SAPROV- MOD. 1011

\section{DEFINIÇÃO DOS CRITÉRIOS DE VALOR} EMPRESA 12.IPM20

Taxa de produção por empregado

Quantidade produzida por homem-hora

Quantidade produzida por horas-máquinas

Quantidade produzida por capital empregado

Quantidade produzida por vendas efetivas

Lucros sobre capital total empregado

$\%$ de perdas de matérias-primas e componentes sólidos

$\%$ de perdas devidas às máquinas e equipamentos

Taxa de utilização das máquinas

$\%$ da planta ocupada com a produção

Cadência de produção

Tempo total de ociosidade das máquinas e equipamentos

Tempo total de preparação e regulação das máquinas

Lead time total de produção

Tempo total de set-up

Tempo total de espera

$\%$ de operadores na categoria multifuncional

Prazo médio de entrega dos pedidos

Número de pontos de estocagem intermediária

Freqüência de intervenções para manutenção preventiva

Quantidade total dos estoques de produtos em elaboração

Quantidade total dos estoques de matérias-primas

Quantidade total dos estoques de produtos acabados

$\%$ da planta ocupada com os estoques

$\%$ de sincronização dos fluxos a montante

$\%$ de sincronização dos fluxos a jusante

Índice de rejeição

$\%$ de devoluções efetivas por questões de qualidade

Número de defeitos por lote de produção

Quantidade de retrabalho

Índice de reclamações do cliente por motivos de qualidade

$\%$ de entregas em atraso ou incompletas

Índice de reclamações do cliente por motivos de prazo

$\%$ de cancelamento dos pedidos

\% dos fornecedores em "Garantia de Qualidade"

Freqüência das panes no processo produtivo

Quantidade de softwares utilizados na produção

Índice de rotatividade da mão-de-obra

Índice de absenteísmo dos empregados

Número de acidentes no trabalho

Nota de QT atribuída pelos grupos de qualidade

Nota de Higiene atribuída pelos grupos de qualidade

de flexibilidade e de qualidade do sistema de manufatura, permitindo que sejam identificados pontos fortes e pontos fracos da estrutura produtiva. Desse modo, o resultado desejado dos índices será sempre aquele igual a 1 , ou seja, quando o resultado efetivo for igual ao resultado padrão.
Ressalta-se, mais uma vez, que os dados apresentados nos formulários de auditoria constituem "dados representativos" dos números informados pela empresa, em atendimento ao contrato de confidencialidade firmado entre esta pesquisa e a empresa analisada. 
Tabela 6 - Matriz dos padrões referenciais de desempenho para a empresa estudada Fonte: SEVERIANO FILHO, 1995

\section{PADRÕES REFERENCIAIS DE DESEMPENHO}

VALORES REPRESENTATIVOS DOS NÚMEROS INFORMADOS PELA EMPRESA

\begin{tabular}{|c|c|}
\hline CRITÉRIOS DE VALOR & PADRÃO \\
\hline $\begin{array}{l}\text { Taxa de produção por empregado } \\
\text { Quantidade produzida por homem-hora } \\
\text { Quantidade produzida por horas-máquinas } \\
\text { Quantidade produzida por capital empregado } \\
\text { Quantidade produzida por vendas efetivas } \\
\text { Lucros sobre capital total empregado } \\
\text { \% de perdas de matérias-primas e componentes sólidos } \\
\text { \% de perdas devidas às máquinas e equipamentos } \\
\text { Taxa de utilização das máquinas } \\
\text { \% da planta ocupada com a produção } \\
\text { Cadência de produção } \\
\text { Tempo total de ociosidade das máquinas e equipamentos } \\
\text { Tempo total de preparação e regulação das máquinas } \\
\text { Lead time total de produção } \\
\text { Tempo total de set-up } \\
\text { Tempo total de espera } \\
\text { \% de operadores na categoria multifuncional } \\
\text { Prazo médio de entrega dos pedidos } \\
\text { Número de pontos de estocagem intermediária } \\
\text { Freqüência de intervenções para manutenção preventiva } \\
\text { Quantidade total dos estoques de produtos em elaboração } \\
\text { Quantidade total dos estoques de matérias-primas } \\
\text { Quantidade total dos estoques de produtos acabados } \\
\text { \% da planta ocupada com os estoques } \\
\text { \% de sincronização dos fluxos a montante } \\
\text { \% de sincronização dos fluxos a jusante } \\
\text { Índice de rejeição } \\
\text { \% de devoluções efetivas por questões de qualidade } \\
\text { Número de defeitos por lote de produção } \\
\text { Quantidade de retrabalho } \\
\text { Índice de reclamações do cliente por motivos de qualidade } \\
\text { \% de entregas em atraso ou incompletas } \\
\text { Índice de reclamações do cliente por motivos de prazo } \\
\text { \% de cancelamento dos pedidos } \\
\text { \% dos fornecedores em "Garantia de Qualidade" } \\
\text { Freqüência das panes no processo produtivo } \\
\text { Quantidade de softwares utilizados na produção } \\
\text { Índice de rotatividade da mão-de-obra } \\
\text { Índice de absenteísmo dos empregados } \\
\text { Índice de acidentes no trabalho } \\
\text { Nota de QT atribuída pelos grupos de qualidade } \\
\text { Nota de Higiene atribuída pelos grupos de qualidade }\end{array}$ & $\begin{array}{c}3.600 / \mathrm{sem} . \\
90.0 \\
300.0 \\
5.00 \\
100.0 \% \\
1.50 \$ \\
1.50 \\
1.90 \\
120 \mathrm{hrs} / \mathrm{sem} . \\
85.0 \\
97.0 \% \\
0.03 \\
2.5 \mathrm{hrs} / \mathrm{sem} . \\
5.5 \mathrm{hrs} \\
1.2 \mathrm{hrs} / \mathrm{sem} . \\
0.04 \\
100.0 \\
1.0 \mathrm{dia} \\
2.00 \\
2.0 / \mathrm{sem} \\
1.0 \mathrm{~d} / \mathrm{prod} . \\
3.0 \mathrm{~d} / \mathrm{prod} . \\
0.5 \mathrm{~d} / \mathrm{prod} . \\
5.0 \\
95.0 \\
82.0 \\
2.50 \\
0.50 \\
15.50 \\
0.8 \% \\
2.00 \\
0.50 \\
3.50 \\
0.50 \\
75.0 \\
0.03 \\
3.00 \\
0.20 \\
0.40 \\
0.05 \\
10.0 \\
10.0 \\
\end{array}$ \\
\hline
\end{tabular}

Conforme pode ser observado nos formulários ilustrados pelas Tabelas 7,8 e 9, dos quarenta e dois critérios de valor listados para as linhas de fabricação, onze deles foram julgados como indutores de produtividade, quinze como indutores de flexibilidade e dezesseis como indutores de qualidade. Esta categorização foi realizada com base na natureza do critério de valor, ou seja, em função do tipo de valor que o critério imprime ao sistema produtivo.

Os valores registrados na última coluna dos formulários indicam as variações entre os resultados 
Tabela 7 - Auditoria de avaliação mod. 1012 - empresa 12.IPM20

Fonte: SEVERIANO FILHO, 1995

SAPROV - MOD. 1012

AUDITORIA PARA AVALIAÇÃO DO DESEMPENHO

FOLHA A

\begin{tabular}{|c|c|c|c|c|}
\hline \multirow[t]{2}{*}{ CRITÉRIOS DE VALOR DA MANUFATURA AVANÇADA } & \multicolumn{4}{|c|}{ AVALIAÇÃO } \\
\hline & $\begin{array}{l}\text { EFETIVO } \\
\text { (1) }\end{array}$ & $\begin{array}{l}\text { PADRÃO } \\
(2)\end{array}$ & $\begin{array}{l}\text { TAXA } \\
(1 / 2)\end{array}$ & $\begin{array}{l}\text { VARIAÇÃO } \\
\%\end{array}$ \\
\hline Índice de rejeição & 2.58 & 2.50 & 1.0320 & 3.20 \\
\hline \% de devoluções efetivas por questões de qualidade & 0.64 & 0.50 & 1.2800 & 28.00 \\
\hline Número de defeitos por lote de produção & 15.50 & 15.00 & 1.0333 & 3.33 \\
\hline Quantidade de retrabalho & 1.10 & 0.80 & 1.3750 & 37.50 \\
\hline Índice de reclamações por motivos de qualidade & 2.90 & 2.00 & 1.4500 & 45.00 \\
\hline$\%$ de entregas em atraso ou incompletas & 0.95 & 0.50 & 1.9000 & 90.00 \\
\hline Índice de reclamações do cliente por motivos de prazo & 3.75 & 3.50 & 1.0714 & 7.14 \\
\hline$\%$ de cancelamento dos pedidos & 1.25 & 0.50 & 2.5000 & 150.00 \\
\hline \% dos fornecedores em "Garantia de Qualidade" & 75.00 & 75.00 & 1.0000 & 0.00 \\
\hline Freqüência das panes no processo produtivo & 0.05 & 0.03 & 1.6666 & 66.66 \\
\hline Quantidade de softwares utilizados na produção & 3.00 & 3.00 & 1.0000 & 0.00 \\
\hline Índice de rotatividade da mão-de-obra & 0.20 & 0.20 & 1.0000 & 0.00 \\
\hline Índice de absenteísmo dos empregados & 0.40 & 0.40 & 1.0000 & 0.00 \\
\hline Índice de acidentes no trabalho & 0.07 & 0.05 & 1.4000 & 40.00 \\
\hline Nota de QT atribuída pelos grupos de qualidade & 10.0 & 10.00 & 1.0000 & 0.00 \\
\hline Nota de Higiene atribuída pelos grupos de qualidade & 10.00 & 10.00 & 1.0000 & 0.00 \\
\hline $\begin{array}{c}\text { DESEMPENHO TOTAL DOS PARÂMETROS DE } \\
\text { VALOR DA QUALIDADE }\end{array}$ & & & 20.7083 & \\
\hline
\end{tabular}

efetivamente alcançados pela empresa e os padrões de excelência por ela estabelecidos. Desse modo, os critérios de valor tanto podem ser avaliados individualmente, ou seja, caso a caso, quanto em conjunto, a partir de grupos de indução de produtividade, de flexibilidade ou de qualidade.

Esse procedimento permitirá a identificação de pontos fortes e de pontos fracos do sistema produtivo, pela apresentação de suas áreas de problemas (focos de fraquezas organizacionais), assim como de suas instâncias de retroalimentação permanente ou em estado de excelência (focos de forças organizacionais). De um modo geral, as constatações efetuadas em relação aos sistemas analisados são as seguintes:

\section{(1) - SOBRE O DESEMPENHO TÉCNICO EM PRODUTIVIDADE DAS LINHAS DE PRODUÇÃO}

No que diz respeito às linhas de fabricação analisadas, o desempenho técnico em produtividade foi medido por onze critérios de valor, conforme demonstrado na Tabela 8. Destes critérios, dois (percentual de perdas devidas às máquinas e equipamentos; e percentual da planta ocupada com a produção) apresentaram desempenho efetivo igual ao desempenho padrão, alcançando assim os níveis de excelência determinados pela empresa. Dessa forma, esses dois critérios representam pontos fortes do sistema de produção, uma vez que caracterizam 
Tabela 8 - Auditoria de avaliação mod. 1013 - empresa 12.IPM20

Fonte: SEVERIANO FILHO, 1995

SAPROV - MOD. 1013

AUDITORIA PARA AVALIAÇÃO DO DESEMPENHO

FOLHA B

\begin{tabular}{l|c|c|c|c}
\hline \multirow{2}{*}{ CRITÉRIOS DE VALOR DA MANUFATURA AVANÇADA } & \multicolumn{4}{|c}{ AVALIAÇÃO } \\
\cline { 2 - 5 } & $\begin{array}{c}\text { EFETIVO } \\
\mathbf{( 1 )}\end{array}$ & $\begin{array}{c}\text { PADRÃO } \\
\mathbf{( 2 )}\end{array}$ & $\begin{array}{c}\text { TAXA } \\
\mathbf{( 1 / 2 )}\end{array}$ & $\begin{array}{c}\text { VARIAÇÃO } \\
\%\end{array}$ \\
\hline Taxa de produção por empregado & 3.120 & 3.600 & 0.8666 & 13.34 \\
\hline Quantidade produzida por homem-hora & 78.00 & 90.00 & 0.8666 & 13.34 \\
\hline Quantidade produzida por horas-máquinas & 200.00 & 300.00 & 0.6666 & 33.33 \\
\hline Quantidade produzida por capital empregado & 4.30 & 5.00 & 0.8600 & 14.00 \\
\hline Quantidade produzida por vendas efetivas & 85.00 & 100.00 & 0.8500 & 15.00 \\
\hline Lucros sobre capital total empregado & 1.40 & 1.50 & 0.9333 & 6.66 \\
\hline \% de perdas de matérias-primas e componentes sólidos & 1.45 & 1.50 & 0.9666 & 3.33 \\
\hline \% de perdas devidas às máquinas e equipamentos & 1.90 & 1.90 & 1.0000 & 0.00 \\
\hline Taxa de utilização das máquinas & 80.00 & 120.00 & 0.6666 & 33.33 \\
\hline \% da planta ocupada com a produção & 85.00 & 85.00 & 1.0000 & 0.00 \\
\hline Cadência de produção & 0.85 & 0.97 & 0.8762 & 12.38 \\
\hline DESEMPENHO TOTAL DOS PARÂMETROS DE & & & & 9.7591 \\
\hline \hline
\end{tabular}

metas de manufatura plenamente alcançadas pela organização.

Dentre os demais critérios analisados, outros dois (percentual de perdas sobre matériasprimas e componentes sólidos; e lucros sobre o capital total empregado) apresentaram baixa variação entre o desempenho real e o desempenho padrão, fixada em 3.33 e $6.66 \%$, respectivamente. Considera-se que esses itens representam também pontos fortes do sistema de manufatura, uma vez que constituem indicadores bastante próximos dos níveis de excelência determinados.

Os sete critérios restantes apresentaram baixo desempenho (todos com variação entre o resultado real e o resultado padrão acima de 10\%), caracterizando áreas de problemas da estrutura de produção. Destes critérios, os que apresentam maiores problemas são, sem dúvida, a quantidade produzida por hora-máquina e a taxa de utilização das máquinas, cuja variação entre o resultado real e o resultado padrão foi de $33.33 \%$

\section{(2) SOBRE O DESEMPENHO TÉCNICO EM FLEXIBILIDADE DAS LINHAS DE PRODUÇÃO}

O desempenho técnico em flexibilidade, por sua vez, foi medido por quinze critérios de valor, cujos resultados estão demonstrados na Tabela 9. Destes critérios, quatro (freqüência de intervenções para manutenção preventiva; \% de sincronização dos fluxos a montante; \% de sincronização dos fluxos a jusante e \% de operadores na categoria multifuncional) atingiram o desempenho padrão definido pela empresa. De acordo com as instruções do modelo, esses quatro critérios indicam metas de excelência, em termos de flexibilidade, alcançadas pela empresa.

Os onze critérios restantes apresentaram baixo desempenho em relação ao resultado padrão, revelando fracos níveis de flexibilidade 
Tabela 9 - Auditoria de avaliação mod. 1014 - empresa 12.IPM20

Fonte: SEVERIANO FILHO, 1995

SAPROV - MOD. 1014

AUDITORIA PARA AVALIAÇÃO DO DESEMPENHO

FOLHA C

\begin{tabular}{|c|c|c|c|c|}
\hline \multirow[t]{2}{*}{ CRITÉRIOS DE VALOR DA MANUFATURA AVANÇADA } & \multicolumn{4}{|c|}{ AVALIAÇÃO } \\
\hline & $\begin{array}{l}\text { EFETIVO } \\
\text { (1) }\end{array}$ & $\begin{array}{l}\text { PADRÃO } \\
(2)\end{array}$ & $\begin{array}{l}\text { TAXA } \\
(1 / 2)\end{array}$ & $\begin{array}{l}\text { VARIAÇÃO } \\
\%\end{array}$ \\
\hline Tempo total de ociosidade das máquinas e equipamentos & 0.07 & 0.03 & 2.3333 & 133.33 \\
\hline Tempo total de preparação e regulação das máquinas & 3.00 & 2.50 & 1.2000 & 20.00 \\
\hline Lead time total de produção & 6.50 & 5.50 & 1.1818 & 18.18 \\
\hline Tempo total de set-up & 1.45 & 1.20 & 1.2083 & 20.83 \\
\hline Tempo total de espera & 0.05 & 0.04 & 1.2500 & 25.00 \\
\hline$\%$ de operadores na categoria multifuncional & 100.00 & 100.00 & 1.0000 & 0.00 \\
\hline Prazo médio de entrega dos pedidos & 1.50 & 1.00 & 1.5000 & 50.00 \\
\hline Número de pontos de estocagem intermediária & 3.00 & 2.00 & 1.5000 & 50.00 \\
\hline Freqüência de intervenções para manutenção preventiva & 2.00 & 2.00 & 1.0000 & 0.00 \\
\hline Quantidade total dos estoques de prod. em elaboração & 1.50 & 1.00 & 1.5000 & 50.00 \\
\hline Quantidade total dos estoques de matérias-primas & 3.50 & 3.00 & 1.1666 & 16.66 \\
\hline Quantidade total dos estoques de produtos acabados & 1.00 & 0.50 & 2.0000 & 100.00 \\
\hline$\%$ da planta ocupada com os estoques & 8.50 & 5.00 & 1.7000 & 70.00 \\
\hline \% de sincronização dos fluxos a montante & 95.00 & 95.00 & 1.0000 & 0.00 \\
\hline \% de sincronização dos fluxos a jusante & 82.00 & 82.00 & 1.0000 & 0.00 \\
\hline $\begin{array}{l}\text { DESEMPENHO TOTAL DOS PARÂMETROS DE } \\
\text { VALOR DA FLEXIBILIDADE }\end{array}$ & & & 20.5350 & \\
\hline
\end{tabular}

do sistema de manufatura. Dos pontos fracos ou áreas de problemas, dois deles chamam a atenção pela alta variação entre o resultado efetivo e o resultado padrão: trata-se do tempo total de ociosidade das máquinas e equipamentos, com variação de $133,33 \%$, e da quantidade total dos estoques de produtos acabados, com $100 \%$ de variação.

\section{(3) SOBRE O DESEMPENHO TÉCNICO EM QUALIDADE DAS LINHAS DE PRODUÇÃO}

Para a avaliação do desempenho técnico em qualidade das linhas de fabricação da empresa utilizaram-se dezesseis critérios de valor, conforme demonstrado na Tabela 7. A auditoria constatou que, destes critérios, apenas seis (quantidade de "softwares" utilizados na produção; índice de absenteísmo dos empregados; nota de QT atribuída pelos grupos de qualidade; nota de higiene atribuída pelos grupos de qualidade; \% de fornecedores em garantia de qualidade $e$ índice de rotatividade da mão-de-obra) atingiram os padrões de referência estabelecidos pela empresa. Portanto, esses critérios representam as metas de excelência em qualidade, alcançadas pela empresa.

Dos dez critérios restantes, três apresentaram baixa variação (inferior a 10\%) entre o desempenho real e o desempenho padrão, colocando-se igualmente como pontos fortes, em termos de qualidade, do sistema produtivo. É o caso do índice de rejeição, com $3.2 \%$ de variação; do número de defeitos por lote de produção, com 
Tabela 10 - Sistema de dados para análise da manufatura nas linhas de produção estudadas Fonte: SEVERIANO FILHO, 1995.

\begin{tabular}{l|r|r|r}
\hline \multicolumn{1}{c|}{$\begin{array}{c}\text { DADOS PARA ANÁLISE DA } \\
\text { MANUFATURA }\end{array}$} & \multicolumn{2}{c}{ EMPRESA 12.IPM20 } \\
\cline { 2 - 4 } & FAB.1 & FAB.2 & FAB.3 \\
\hline Número de critérios de valor da produtividade (Ncvp) & 11 & 11 & 11 \\
\hline Número de critérios de valor da flexibilidade (Ncvf) & 15 & 15 & 15 \\
\hline Número de critérios de valor de qualidade (Ncvq) & 16 & 16 & 16 \\
\hline Soma parâmetros de valor da produtividade (Sdpp) & 9.7591 & 9.7591 & 9.7591 \\
\hline Soma parâmetros de valor da flexibilidade (Sdpf) & 20.5350 & 20.5350 & 20.5350 \\
\hline Soma parâmetros de valor da qualidade (Sdpq) & 20.7083 & 20.7083 & 20.7083 \\
\hline Output total produzido (Otp) & 124.800 & 137.280 & 162.240 \\
\hline Preço deflacionado da unid. de prod. vendido (Pv) & 0.08 & 0.10 & 0.09 \\
\hline Custo total da mão-de-obra (Cmo) & 3.540 .0 & 3.894 .0 & 4.602 \\
\hline Custo dos materiais empregados (Cmt) & 839.00 & 918.50 & 1.120 \\
\hline Custo de depreciação (Ca) & 325.80 & 358.38 & 423.54 \\
\hline Custo de máquinas e equipamentos (Cm) & 119.30 & 131.23 & 155.09 \\
\hline Custo de ferramentas (Cf) & 55.20 & 60.72 & 71.76 \\
\hline Custo do chão de fábrica (Cp) & 48.00 & 52.80 & 62.40 \\
\hline Custo dos softwares utilizados (Cs) & 31.50 & 31.50 & 31.50 \\
\hline Custo total de set-up (Cup) & 65.70 & 65.70 & 65.70 \\
\hline Custo total de espera (Cw) & 43.00 & 43.00 & 43.00 \\
\hline Custo de ociosidade (Coc) & 85.60 & 85.60 & 85.60 \\
\hline Custo de estoques (Ci) & 101.50 & 111.65 & 131.95 \\
\hline Custo de prevenção (Cpv) & 25.50 & 25.50 & 25.50 \\
\hline Custo de falhas (Cdf) & 34.70 & 34.70 & 34.70 \\
\hline \hline
\end{tabular}

3.33\%; e do índice de reclamações por motivos de qualidade, com $7.14 \%$. Esta constatação indica o nível de seriedade do programa de TQC implantado pela empresa, cujos resultados começam a ser observados em diversos pontos da organização.

Entre os sete critérios com desempenhos considerados muito baixos, um deles (percentual de cancelamento dos pedidos) apresentou elevada variação na taxa de desempenho, caracterizando assim o ponto de maior problema das linhas, no que diz respeito à qualidade.

A avaliação desses critérios de valor permitiu a formulação parcial de uma base de dados específica sobre os sistemas de manufatura empregados, a qual é utilizada na avaliação do desempenho global da produção das unidades analisadas. Desse modo, as informações geradas foram utilizadas na aplicação dos indicadores de base do modelo, com o objetivo de avaliar o desempenho técnico e econômico da manufatura. Observe que essas informações são específicas das linhas estudadas, evidenciando-se portanto, o caráter exclusivo e absoluto das mesmas, para fins de uso e aplicação.

\subsection{Aplicação dos Indicadores de Base para a Avaliação do Desempenho da Manufatura}

O quarto e último procedimento operacional do Sistema SAPROV, segundo suas instruções normativas, diz respeito à aplicação dos indicadores de base, cuja finalidade é a avaliação do desempenho técnico e econômico da produção. Para a execução desta operação, definiu-se um sistema de dados sobre a produção realizada nas três linhas estudadas, conforme ilustração da Tabela 10. 
Tabela 11 - Folha de cálculo da empresa 12.IPM20 - aplicação dos indicadores básicos Fonte: SEVERIANO FILHO, 1995

\begin{tabular}{|c|c|c|c|}
\hline EMPRESA 12.IPM20 & \multicolumn{3}{|c|}{ CONFIGURAÇÃO DE CÁLCULOS E RESULTADOS } \\
\hline INDICADORES & LINHA 1 & LINHA 2 & LINHA 3 \\
\hline $\begin{array}{c}\text { ÍNDICE DE INDUÇÃO DE PRODUTIVIDADE } \\
\qquad \begin{array}{ll}\text { IIP }=(\text { Sdpp } & \text { Ncvp }) \\
100\end{array}\end{array}$ & $\begin{array}{c}\text { IIP }=\left(\begin{array}{cc}9.7591 & 11\end{array}\right) \quad 100 \\
I I P=88.7\end{array}$ & $\begin{array}{c}\text { IIP }=\left(\begin{array}{cc}9.7591 & 11\end{array}\right) \quad 100 \\
I I P=88.7\end{array}$ & $\begin{array}{c}\text { IIP }=\left(\begin{array}{cc}9.7591 & 11\end{array}\right) \quad 100 \\
I I P=88.7\end{array}$ \\
\hline 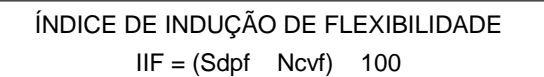 & $\begin{array}{c}\text { IIF }=\left(\begin{array}{cc}20.5350 & 15\end{array}\right) \quad 100 \\
I I F=136.9\end{array}$ & $\begin{array}{c}\mathrm{IIF}=\left(\begin{array}{cc}20.5350 & 15\end{array}\right) \quad 100 \\
\mathrm{IIF}=136.9\end{array}$ & $\begin{array}{c}\mathrm{IIF}=\left(\begin{array}{cc}20.5350 & 15\end{array}\right) \quad 100 \\
\mathrm{IIF}=136.9\end{array}$ \\
\hline $\begin{array}{l}\text { ÍNDICE DE INDUÇÃO DE QUALIDADE } \\
\qquad I Q=\left(\begin{array}{ll}\text { Sdpq } & \text { Ncvq }\end{array}\right) 100\end{array}$ & $\begin{array}{c}\mathrm{IIQ}=\left(\begin{array}{cc}20.7083 & 16\end{array}\right) \quad 100 \\
\mathrm{IIQ}=129.42\end{array}$ & $\begin{array}{c}\mathrm{IIQ}=\left(\begin{array}{cc}20.7083 & 16\end{array}\right) \quad 100 \\
\mathrm{IIQ}=129.42\end{array}$ & $\begin{array}{c}\mathrm{IIQ}=\left(\begin{array}{cc}20.7083 & 16\end{array}\right) \quad 100 \\
I \mathrm{Q}=129.42\end{array}$ \\
\hline 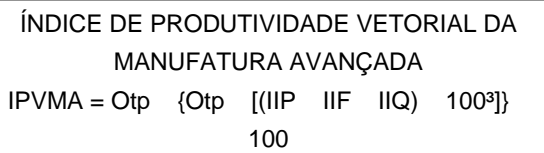 & $\begin{array}{c}\text { IPVMA }=(124.800) \\
(124.800 \quad 1.5715) \quad 100 \\
\text { IPVMA }=63.63\end{array}$ & $\begin{array}{c}\text { IPVMA }=(137.280) \\
(137.280 \quad 1.5715) \quad 100 \\
\text { IPVMA }=63.63\end{array}$ & $\begin{array}{c}\text { IPVMA }=(162.240) \\
(162.240 \quad 1.5715) \quad 100 \\
\text { IPVMA }=63.63\end{array}$ \\
\hline 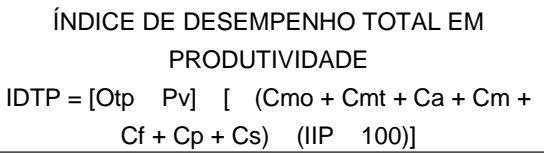 & $\begin{array}{c}\text { IDTP }=\left(\begin{array}{cc}124.800 & 0.08\end{array}\right) \\
\left(\begin{array}{cc}4.958 .80 & 0.887\end{array}\right) \\
\text { IDTP }=2.27\end{array}$ & $\begin{array}{c}\text { IDTP }=\left(\begin{array}{cc}137.280 & 0.10\end{array}\right) \\
\left(\begin{array}{cc}5.447 .13 \quad 0.887\end{array}\right) \\
\text { IDTP }=2.84\end{array}$ & $\begin{array}{c}\text { IDTP }=\left(\begin{array}{cc}162.240 & 0.09\end{array}\right) \\
\left(\begin{array}{cc}6.466 .29 \quad 0.887\end{array}\right) \\
\text { IDTP }=2.54\end{array}$ \\
\hline 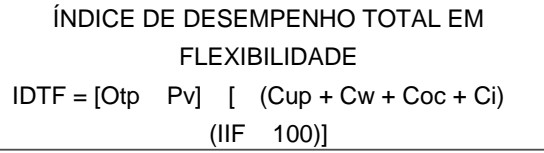 & $\begin{array}{c}\text { IDTF }=\left(\begin{array}{ll}124.800 & 0.08\end{array}\right) \\
\left(\begin{array}{ll}295.80 & 1.369\end{array}\right) \\
\text { IDTF }=24.65\end{array}$ & $\begin{array}{c}\text { IDTF }=\left(\begin{array}{cc}137.280 & 0.10\end{array}\right) \\
\left(\begin{array}{cc}305.95 & 1.369\end{array}\right) \\
\text { IDTF }=32.77\end{array}$ & 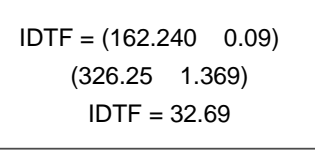 \\
\hline $\begin{array}{l}\text { ÍNDICE DE DESEMPENHO TOTAL EM } \\
\text { QUALIDADE } \\
\text { IDTQ = }\left[\begin{array}{lllll}\text { Otp } & \text { Pv }\end{array}\right] \\
\end{array}$ & $\begin{array}{l}\text { IDTQ }=\left(\begin{array}{ll}124.800 & 0.08\end{array}\right) \\
\left(\begin{array}{ll}60.20 & 1.294\end{array}\right) \\
\text { IDTQ }=128.26\end{array}$ & 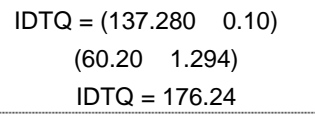 & 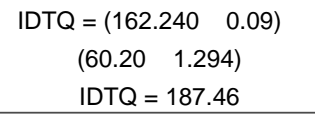 \\
\hline $\begin{array}{l}\text { ÍNDICE DE DESEMPENHO VETORIAL DA } \\
\text { MANUFATURA AVANÇADA } \\
\left.\begin{array}{rl}\text { IDVMA = } & {\left[\begin{array}{lll}\text { Otp } & \text { PV }\end{array}\right] \quad\left[\begin{array}{lll}C P & (I I P & 100\end{array}\right)+C F} \\
& \left(\begin{array}{ll}I I F & 100\end{array}\right)+C Q \quad\left(\begin{array}{ll}\text { III } & 100\end{array}\right]\end{array}\right]\end{array}$ & 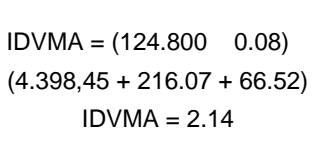 & 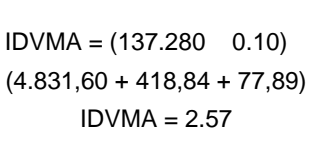 & $\begin{array}{c}\text { IDVMA }=\left(\begin{array}{ll}162.240 & 0.09\end{array}\right) \\
(5.735,59+446,63+77,89) \\
\text { IDVMA }=2.33\end{array}$ \\
\hline
\end{tabular}

Na prática, os indicadores de base constituem uma matriz geral para a avaliação da produtividade, formada por 8 índices de desempenho, sendo 6 de natureza parcial e 2 de natureza global (agregado), estando todos baseados no conceito de produtividade vetorial da manufatura.

As operações de aplicação desses indicadores foram feitas de acordo com o Modelo de Referência SAPROV 1015, utilizando como base de cálculo as informações constantes do Sistema de Dados para Análise da Manufatura, referente às unidades de produção analisadas.

Desse modo, e em conformidade com as instruções do modelo proposto, efetuou-se a avaliação do desempenho técnico e econômico da manufatura, nas três linhas de fabricação analisadas. Para cada uma das linhas, utilizou-se os oito indicadores básicos, calculando-se, em folhas específicas, os resultados obtidos. A Tabela 11 ilustra a execução operacional destes indicadores e suas respectivas configurações de cálculo.

Observe que o desempenho técnico das linhas foi medido utilizando os quatro primeiros indicadores, sendo que três deles (IIP, IIF e IIQ) correspondem a medidas parciais e apenas um (IPVMA) constitui uma medida global de produtividade. Tanto para as medidas parciais, quanto para o indicador global, utilizou-se uma base de cálculo comum para as três linhas de fabricação, em conformidade com a auditoria dos dados, que considerou serem similares as características operacionais e tecnológicas dessas linhas.

$\mathrm{O}$ índice de indução de produtividade, que indica a diferença ou o distanciamento entre a produtividade programada para o sistema e a produtividade efetivamente alcançada, apresen- 
tou um resultado médio equivalente a 88.7. Este resultado indica a existência de um diferencial de produtividade (produtividade padrão menos produtividade efetiva) em torno de $11,3 \%$, o que caracteriza uma boa medida de desempenho. Note-se que essa medida está bastante próxima da medida padrão (IIP = 100), apontando assim a excelente reação da empresa às ações de melhoramento da produtividade, nas três linhas de produção analisadas.

Com relação ao índice de indução de flexibilidade, o resultado alcançado apontou uma diferença média de 36,9\% entre a flexibilidade programada e a flexibilidade efetiva, indicando assim um considerável nível de falhas na capacidade reativa da empresa. Este resultado indica também uma certa incongruência entre as ações de melhoramento da produtividade, de um lado, e as de melhoria da flexibilidade, do outro, ilustrando a incapacidade da empresa de produzir melhoramentos simultâneos nos diferentes aspectos da estrutura produtiva.

$\mathrm{O}$ índice de indução de qualidade, por sua vez, apresentou um resultado correspondente a 129.42, induzindo uma diferença média entre a qualidade padrão e a qualidade efetiva em torno de 29,42\%. Observe que este resultado é bastante próximo do resultado assumido pelo IIF, o que indica a existência de uma forte correlação entre as intervenções de melhoria da flexibilidade e as ações de TQM, implantadas pela empresa.

$\mathrm{O}$ índice de produtividade vetorial da manufatura avançada indica a relação entre a produção total efetiva e o padrão de excelência produtiva. O padrão de excelência é determinado pela organização, estando expresso na equação pelos indicadores IIP, IIF e IIQ. Para o caso das linhas analisadas, este índice foi de 62,63, indicando que foram alcançadas mais de 60\% das metas de excelência, estabelecidas pela empresa. Conforme foi salientado, o IPVMA é uma medida global e vetorial do desempenho técnico da manufatura, de modo que este resultado constitui um vetor técnico de atributos, referente à produção realizada em cada uma das linhas de fabricação estudadas.
Do ponto de vista da avaliação e acompanhamento da produção, a aplicação desses indicadores constitui apenas um exercício parcial de avaliação. $\mathrm{Na}$ verdade, os resultados verificados devem ser continuamente controlados e comparados no tempo, por igual exercício de avaliação, com periodicidade curta (mensal, bimestral ou trimestral). Nesse sentido, o modelo permite tanto a comparação sistematizada e dinâmica dos resultados alcançados, para fins de avaliação e tomada de decisões, quanto o ajustamento de critérios e parâmetros julgados pertinentes ao processo de avaliação.

O desempenho econômico das linhas foi medido pelos quatro últimos indicadores (IDTP, IDTF, IDTQ e IDVMA), sendo que os três primeiros constituem medidas parciais de produtividade econômica e o último, uma medida global de desempenho.

$\mathrm{O}$ índice de desempenho total em produtividade estabelece a relação entre o resultado total da produção e os custos específicos de produtividade. Observe que o somatório desses custos constitui um vetor de atributos da linha de fabricação, na medida em que os seus valores são ponderados pelo índice de indução em produtividade. De acordo com a folha de cálculo da Tabela 11, os valores de IDTP calculados para as linhas 1 , 2 e 3 indicam que o resultado econômico da produção, nessas linhas, cobrem 2.27, 2.84 e 2.54 vezes, respectivamente, o montante de seus custos de produtividade.

Em se tratando de um indicador econômico de produtividade, que relaciona receitas e despesas de produção, a presença do IIP na equação do IDTP tem a função de um fator de ponderação, cujo valor representa o indutor de atributos referente às metas de excelência em produtividade, estabelecidas para as unidades de produção em referência. Nesse sentido, quanto mais próximo estiver o IIP de seu valor padrão (IIP = 100), maior será o resultado apontado pelo IDTP. Nessa mesma ordem de consideração, uma diminuição dos custos de produtividade fará com que a relação expressa pelo IDTP seja maior. 
O índice de desempenho total em flexibilidade é uma medida parcial de produtividade, que aponta a relação entre o valor total da produção e o custo de flexibilidade do sistema produtivo. Esse indicador assume a mesma lógica de operação do IDTP, tendo seu valor ponderado pelos atributos de excelência em flexibilidade, definidos pela empresa. Os resultados verificados de 24.65, 32.77 e 32.69 para as linhas de fabricação 1 , 2 e 3 , respectivamente, indicam a proporção em que os custos ponderados de flexibilidade foram cobertos pela produção realizada.

No limite de alcance dos padrões de excelência da empresa, esta relação seria dada apenas pelos valores da produção e dos custos. Considerando a tendência de redução permanente destes últimos, em função das ações de melhoramento da flexibilidade do sistema, podese aferir que o resultado do IDTF deve apresentar variações positivas, nos sucessivos intervalos do exercício de avaliação.

$\mathrm{O}$ índice de desempenho total em qualidade é também uma medida parcial de produtividade, que indica o desempenho econômico relacionado com o valor da produção e os custos de qualidade da linha de fabricação. A aplicação do IDTQ, nas unidades analisadas, apontou desempenhos de 128.26, 176.24 e 187.46, para as linhas de produção 1 , 2 e 3 , respectivamente, conforme ilustração da Tabela 11.

Estes resultados revelam a proporção em que os custos de qualidade foram cobertos pelo valor da produção, constituindo-se em indicadores do sistema de qualidade, para cada uma das linhas estudadas. Assim sendo, o controle e monitoramento do comportamento desses números pressupõem a sistematização do exercício periódico de avaliação, que permite a comparação, no tempo, dos resultados alcançados em cada processo de avaliação.

$\mathrm{O}$ índice de desempenho vetorial da manufatura avançada é uma medida global e vetorial de produtividade econômica do sistema produtivo, que indica a relação entre o valor total da produção e o montante dos custos gerados pelo sistema de manufatura. A estrutura de custos, organizada de acordo com a natureza operacional de seus valores (de produtividade, de flexibilidade e de qualidade), foi ponderada em função de seus respectivos indicadores técnicos, quais sejam, o IIP, o IIF e o IIQ. Desse modo, os resultados alcançados pelo IDVMA devem ser interpretados como vetores de atributos econômicos das linhas de produção, na medida em que refletem, também, a inferência dos critérios de valor estabelecidos para cada linha em particular.

Dos resultados obtidos $(2.14,2.57$ e 2.33 , para as linhas 1,2 e 3 , respectivamente), o melhor deles é, sem dúvida, o da linha de fabricação 2. Este resultado indica que as receitas de produção da linha cobrem 2.57 vezes os custos requeridos em seu processo de fabricação.

\section{Conclusões}

— m função das características metodológicas deste trabalho, o exercício de apresentação e análise dos resultados da pesquisa corresponde, na prática, ao processo de aplicação e teste do modelo proposto. Desse modo, as considerações extraídas deste processo estão muito mais relacionadas com a execução efetiva de seus quatro procedimentos operacionais, do que mesmo com o comportamento dos dados numéricos, decorrentes desta aplicação.

Neste sentido, observa-se que os procedimentos técnicos do modelo SAPROV são de fácil operacionalização, não apresentando nenhuma dificuldade que possa ser considerada restritiva, no conjunto de suas operações de execução. Tratam-se, na verdade, de procedimentos simples de avaliação, que formam um sistema lógico e agregado, voltado à análise e verificação da produtividade global de uma estrutura produtiva.

A experiência de aplicação nas três linhas analisadas constatou que o processo de avaliação pertinente ao modelo apresenta basicamente duas dimensões: uma dimensão técnica e uma econômica. Estas dimensões, apesar de integrarem conceitos e indicadores diferentes, estão inter-relacionadas quanto aos objetivos do 
modelo, de modo que não podem ser utilizadas separadamente, sob quaisquer hipóteses.

No que diz respeito à dimensão técnica, constatou-se a possibilidade de que várias linhas de fabricação de uma mesma empresa, comportando características organizacionais e tecnológicas similares, possam ser avaliadas conjuntamente, sem prejuízo ou restrição de valores para as variáveis consideradas. Neste aspecto, a condição estabelecida é a de que sejam definidos critérios de valor idênticos, para os sistemas em análise.

Observou-se igualmente, que a avaliação de desempenho com base em critérios de valor constitui um processo sobretudo dinâmico e flexível de aferição de resultados, dadas as características de seus procedimentos operacio- nais. Assim sendo, este processo permite a livre alteração (inclusão e exclusão) de variáveis, mantendo inalterada a estrutura de avaliação do modelo. A formatação do número de critérios de valor, por exemplo, ou mesmo o parâmetro de excelência destes critérios, constituem um exercício dinâmico e flexível de definição, a ser administrado pelas equipes de avaliação.

Uma outra conclusão importante, já salientada na seção anterior, é que este processo de avaliação requer a comparação, no tempo, dos resultados obtidos, com aqueles verificados em outros exercícios de avaliação. Para fins de validade e sustentação do processo, esta comparação deve ocorrer entre os indicadores de uma mesma linha de produção e, nunca, entre os indicadores de linhas diferentes.

\section{Referências Bibliográficas}

KAPLAN, R.S.: "Measuring Manufacturing Performance: a new challenge for managerial accouting research.” International Journal of Production Research, v.5, n.4, 1983.

KULATILAKA, N.: "Financial economic and strategic issues concerning the decision to invest in advanced automation.” International Journal of Production Research, v.13,, pp.241-262, 1984.

MEREDITH, J.: “Justification techniques for advanced manufacturing systems.” International Journal of Production Research, v.24, n.5, pp.1043-1057, 1986.

MILTENBURG, G.L. \& KRINSKY, I.: “Evaluating flexible manufacturing systems.” IIEE Transactions, jun., pp.222-233, 1987.

MOERMAN, P.A.: "Economic evaluation of investments in new production technologies." Engineering Costs and Production Economic, v.13, pp.241-262, 1988.

MOHANTY, R.P. \& RASTOGI, S.C.: "An action research approach to productivity measurement." International Journal of Operations and Production Management, v.6, n.412, pp.47-61, 1986.

PARK, C.S. \& SON, Y.: "An economic evaluation model for advanced manufacturing systems." The Engineering Economist, v.34, n.1, pp.1-26, 1988.
RICHARDSON, P.R. \& GORDON, J.R.: "Measuring total manufacturing performance." Sloan Management Review, pp.47-58, winter, 1980.

SEVERIANO FILHO, C.: O enfoque vetorial da produtividade em uma sistema de avaliação para a manufatura avançada na indústria de alimentos. Tese de Doutorado. UFSC/IGIA, 1995.

SON, Y.: "Economic measure of productivity, quality and flexibility in advanced manufacturing systems.” Journal of Manufacturing Systemson Research, v.6, n.3, pp.197-207, 1987.

SON, Y.: An economic evaluation model for advanced manufacturing systems. (Tese de Doutorado), Auburn University, USA, 1987a.

SON, Y.: "A performance measurement method which remedies the productivity paradox." Production and Invenctory Management Journal, v.31, n.2, pp.38-43, 1990.

SON, Y.: “A framework for modern manufacturing economics.” International Journal of Production Research, v.29, n.12, pp.2483-2499, 1991.

WEILL, P.; SAMSON, D.A. \& SOHAL, A.S.: "Advanced manufacturing echnology: an analysis of practice”. IJTM, Special Issue on Manufacturing Strategy, pp.335-353, 1991. 


\title{
PERFORMANCE MEASUREMENT OF THREE WORK STATIONS INSTALLED IN ADVANCED MANUFACTURING ENVIRONMENTS UTILIZING THE SAPROV MODEL
}

\begin{abstract}
This study evaluated the performance, in terms of productivity, flexibility and quality, of three work stations installed in advanced manufacturing environments, utilizing the SAPROV Model. The research showed that the correlation between productivity, flexibility and quality is not directly proportional to investments made in these functional areas of the factory. This observation was obtained by using the SAPROV methodology, which consists of result the following four operational steps: determination of the manufacturing criteria of value; determination of the referential performance standards for each criterion of value; audit for evaluating the performance of the manufacturing criteria of value; application of the indicators for evaluation of the technical and economical manufacturing performance.
\end{abstract}

Key words: advanced manufacturing; quality; productivity; flexibility; SAPROV Model. 